\title{
Modification of Aluminium 6063 Microstructure by Adding Boron and Titanium to Improve the Thermal Conductivity
}

\author{
Maher Shaira $(\mathbb{D})$ and Suleiman Yousef \\ Faculty of Mechanical and Electrical Engineering, Al-Baath University, Homs, Syria \\ Correspondence should be addressed to Maher Shaira; m_shaira@yahoo.fr
}

Received 2 October 2017; Revised 1 December 2017; Accepted 21 December 2017; Published 24 January 2018

Academic Editor: Necmettin Maraşlı

Copyright (C) 2018 Maher Shaira and Suleiman Yousef. This is an open access article distributed under the Creative Commons Attribution License, which permits unrestricted use, distribution, and reproduction in any medium, provided the original work is properly cited.

\begin{abstract}
This study aimed to improve the thermal conductivity of the Aluminium 6063 for heat sinks applications used in Central Processing Unit (CPU) of computers. Several studies had used different additional elements for this goal. In this paper, we studied the influence of Titanium and Boron addition on the thermal conductivity of Aluminium 6063. Several casting alloys samples were prepared with different percentage of addition elements and then heat-treated by homogenization and aging treatments. The results showed an important modification in thermal conductivity value per rapport to the reference metal, depending on the element of addition and its percentage. The bigger evolution was by using Boron in small percentage. More than $13 \%$ of the improvement was realized in the thermal conductivity with the addition of only $0.05 \%$ of Boron.
\end{abstract}

\section{Introduction}

The electronic machines are in a great development every day. The improvements of their performance stay the principal objective. Central Processing Unit (CPU) of computer is the most important element and produces heat very quickly. Uncontrolled excess heat can damage it [1]. So, heat must be dissipated quickly via heat sink elements. If the dissipation of heat which is produced from the semiconductors elements is not done, many problems can occur in computers and other electronic machines. The heat sinks are very important elements to outflow the heat from those machines to keep them in good performance of work and long life.

In computer, the heat can be produced in excessive quantity especially in the Central Processing Unit. The dissipation of heat must occur easily and quickly for keeping CPU enough coolness and to allow the electronic machines to work correctly along with its employment [2-4].

With the high development of the informatics technology, the microprocessor power dissipation is constantly increasing. In addition, the decrease of microprocessor size has also resulted in higher heat fluxes. The growth of information technology has rapidly increased over the past few years, causing increase in the demand for a microprocessor that has a very high computing ability [5].

Different materials can be used in heat sink components for dissipation of accumulated heat in computer. Depending on the thermal conductivity values, there are different propositions of materials as pure metals or composite materials. Copper can be used also for this goal. Diamond is a very good one but it is very expensive [6]. Aluminium is a popular choice of metals for its characteristics and it is a favourable metal that combines high conductivity and low cost. So, it is usually used in heat sinks of Central Processing Unit of computers $[7,8]$.

Several studies had been carried out in this filed to reduce and dissipate heat produced in those components; some studies tried to calculate and estimate the temperature evacuated from the CPU [1] and the influence of its engineering design on its performance [9]; others studied the improvement of heat dissipation by fabrication of microchannels in the semiconductor elements [10]. Kang et al. tried to improve the heat dissipation by adding closed loop of liquid [11]. Few studies tried to improve the thermal conductivity of heat sink of Central Processing Unit. Some studies tried to use the heat sink as metallic foam to transport the heat by solid conduction and thermal radiation [12]. 
TABle 1: Composition of Aluminium 6063 (at\%).

\begin{tabular}{lcccccccc}
\hline $\mathrm{Si}$ & $\mathrm{Fe}$ & $\mathrm{Cu}$ & $\mathrm{Mn}$ & $\mathrm{Mg}$ & $\mathrm{Zn}$ & $\mathrm{Ni}$ & $\mathrm{Cr}$ & $\mathrm{Ti}$ \\
\hline 0.579 & 0.2124 & 0.0017 & 0.0304 & 0.4584 & 0.002 & 0.0076 & 0.0045 & 0.0118 \\
\hline
\end{tabular}

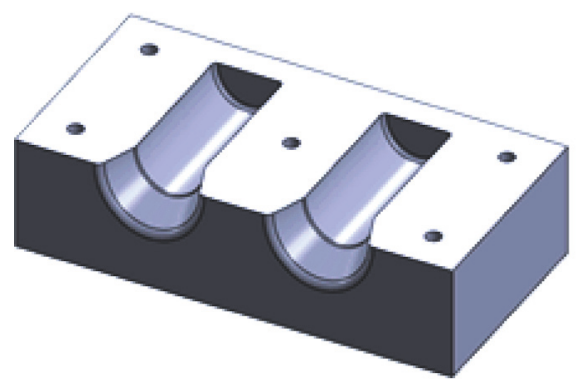

FIgURE 1: Aluminium casting mould with two specimens.

Aluminium characteristics can be improved per the elaboration and heat treatment $[4,7]$ or by cladding [13]. Rana and others studied the influence of different elements on the microstructure and on the mechanical proprieties of Aluminium such as Copper, Magnesium, Silicon, Titanium, Boron, Chrome, and Zirconium [14]. Others studied the influence of metallurgical effect of Titanium and Boron on the thermal conductivity of Aluminium alloy. Those added elements lead to increasing the thermal conductivity $[7,15]$.

But Shin et al. found that the addition of Silicon and Magnesium leads to reducing the thermal conductivity [16]. Nickel addition leads to reducing the thermal and the electrical conductivities due to formation of intermetallic phases, and the bigger thermal conductivity values the smaller grains size; this study showed that the improvement occurs for the mechanical propriety and the thermal conductivity of Aluminium-Silicon alloys [17]. Removing of Vanadium and Zirconium elements form the cast Aluminium leads to improving the electrical and thermal conductivities, in addition to the improvement of measured conductivities [18].

So, alloy composition and thermal history were the most important factors that determine thermal conductivity [7].

\section{Material and Experimental Proceeding}

2.1. Material. Among the series 6000 of Aluminium, we tried to analyze some commercial heat sinks. Aluminium 6063 material was used in this study; the chemical composition is presented in the Table 1 .

Aluminium 6063 bar was cut into a small pieces and melt in a furnace at $850^{\circ} \mathrm{C}$. Boron and Titanium were added during melting of the alloys.

A steel casting mould of tow cylindrical specimens of $33 \mathrm{~mm}$ of diameter is already machined as shown in Figure 1 and is preheated to $200^{\circ} \mathrm{C}$.

The melting of Aluminium with the addition elements is very well mixed into the furnace and in the melting pot until the moment of casting in the moulds. After specimens

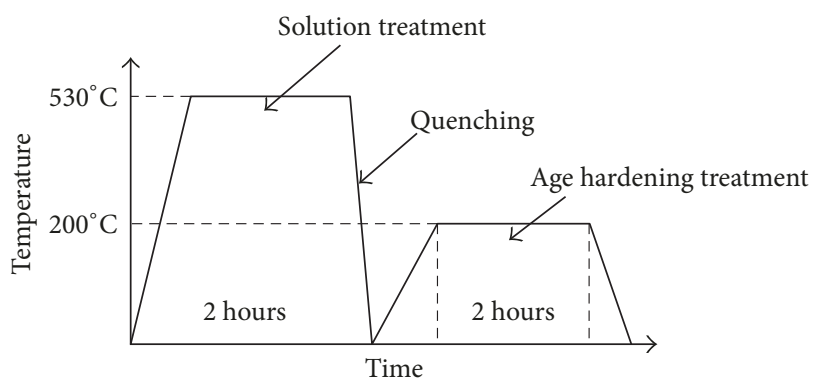

FIGURE 2: Treatments diagram of samples: heating ramp of solution treatment was $530^{\circ} \mathrm{C}$ and for the age hardening treatment it was $200^{\circ} \mathrm{C}$.

casting, the specimens are heat-treated in homogenizing treatment at $530^{\circ} \mathrm{C}$ for $3 \mathrm{hr}$ [19].

The specimens of cylindrical bars are heat-treated in second treatment by aging treatment for $2 \mathrm{hr}$ at $200^{\circ} \mathrm{C}$ after solution treatment at $530^{\circ} \mathrm{C}$ for $2 \mathrm{hr}$ and water quenching as shown in Figure 2.

For each bar sample, about $13 \mathrm{~mm}$ of thickness is cut at the two edges of the sample. The bar of $95 \mathrm{~mm}$ in length is then cut and machined in several specimens for the thermal conductivity measurements.

For each final specimen, a spectrometer analysis was also achieved in the two surface sides of the specimen using Analytical Instruments SPECTROLAB to have the real percentage of chemical elements in the metal after casting.

All specimens have the same compositions of elements, except that the percentage of Boron and Titanium was changed depending on the prepared alloys.

2.2. Thermal Conductivity Measurements. Specimens of thermal conductivity measurements were prepared with $31 \mathrm{~mm}$ of diameter and $30 \mathrm{~mm}$ of thickness, and all these specimens were put in the device of thermal conductivity measurement.

We used ARMFIELD (Heat Transfer and Thermodynamics HT10XC Computer Controlled Heat Transfer) device. The device depends on measuring the temperature between two positions of the sample and during the flowing of the heat through the sample. Thermocouples can give the temperatures to the device which are displayed on screens, as seen in Figure 3. The two sides of the sample are at different temperatures. The top side of the sample is in touch with the heater of the device, and the other side is cooled with constant flow of water.

The principle of measurement depends on the knowledge of heat flow equation through the specimen, Fourier's law, and then we can calculate the conductivity factor: $K(\mathrm{~W} / \mathrm{m} \mathrm{C})[1$, $2,8,12]$.

The heat transfer flow via the specimen can be given by (1). In addition, the conductivity factor $(K)$ can be given by 


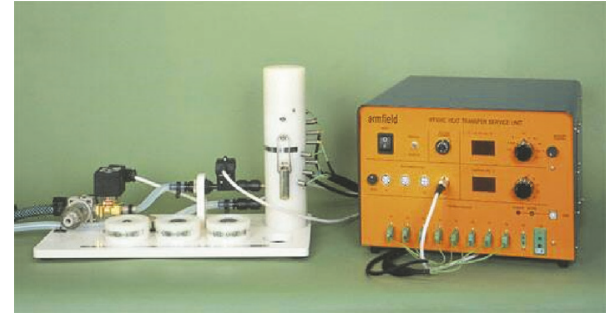

FIGURE 3: Thermal conductivity device with calibration samples.

TABle 2: Parameters of measurements on the thermal conductivity device.

\begin{tabular}{lccc}
\hline$I(\mathrm{~A})$ & $V(\mathrm{v})$ & $\Delta x(\mathrm{~m})$ & $A\left(\mathrm{~m}^{2}\right)[D=31 \mathrm{~mm}]$ \\
\hline 1.87 & 17.8 & 0.015 & 0.000754 \\
\hline
\end{tabular}

(3). $Q$ is the heat flow. It is an energy; it can be given by (4).

$$
\begin{aligned}
Q & =q \cdot A=\frac{K \cdot A \cdot \Delta T}{\Delta x}(\mathrm{~W}), \\
A & =\frac{\pi D^{2}}{4} \\
K & =\frac{\Delta x \cdot \mathrm{Q}}{\Delta T \cdot A}(\mathrm{~W} / \mathrm{m} \mathrm{C}), \\
Q & =V \cdot I(\mathrm{~W}) .
\end{aligned}
$$

For the measurements on the device, all the parameters are fixed as is shown in Table 2. And $\Delta T$ is given by the device for each specimen.

\section{Results and Discussion}

3.1. Thermal Conductivity Results. Two groups of casting specimens were done using the Aluminium 6063, with the addition of Boron and Titanium powder as addition elements.

The first group is the specimen with Titanium addition at different percentages. Table 3 shows the results of specimens after casting and spectrometer analysis.

The second group is with Boron addition as shown in Table 4.

The measurements of thermal conductivity were done to all thermal conductivity specimens. The thermal conductivity value of the references specimens (Aluminium 6063 without any addition elements) was $190.2(\mathrm{~W} / \mathrm{m} \mathrm{C})$.

For all specimens, we measured $\Delta T(\mathrm{C})$ via the thermal conductivity device, we repeated the measurement several times, and mean was recorded. The thermal conductivity value was calculated using (3) and (4).

The measurements of $\Delta T$ in the device were done after stabilization of heat flow through the specimen and when the temperature of the cooled surface was between 30 and $40^{\circ} \mathrm{C}$. This range of temperatures is chosen to obtain a considered heat flow through the sample and to reduce the effect of heat losses by radiation and conversion effects in the device.
TABLE 3: Titanium addition to Aluminium 6063.

\begin{tabular}{lc}
\hline Specimen reference & Ti wt $\%$ \\
\hline Ti-1 & 0.1 \\
Ti-2 & 0.3 \\
Ti-3 & 0.5 \\
Ti-4 & 1 \\
Ti-5 & 1.5 \\
Ti-6 & 2 \\
Ti-7 & 2.5 \\
Ti-8 & 3 \\
\hline
\end{tabular}

TABle 4: Boron addition to Aluminium 6063.

\begin{tabular}{lc}
\hline Specimen reference & B wt $\%$ \\
\hline B-1 & 0.001 \\
B-2 & 0.01 \\
B-3 & 0.05 \\
B-4 & 0.07 \\
B-5 & 0.5 \\
B-6 & 1 \\
B-7 & 1.5 \\
B-8 & 2 \\
\hline
\end{tabular}

The temperatures of samples are still in a small range of measurement. The advantage is to eliminate the influence of temperature change on the thermal conductivity coefficient K.

The thermal conductivity values are calculated. Figure 4 shows the evolution of the thermal conductivity values in function of Titanium percentage in this group.

The curve starts with a strong increase in thermal conductivity value until $0.3 \%$ of Titanium, and then it falls down quickly to a low level of thermal conductivity value of nearly $162 \mathrm{~W} / \mathrm{m} \mathrm{C}$.

The thermal conductivity values in function to the Boron percentages present almost in a similar evolution but with different points of evolution as presented in Figure 5. A peak in the curve can be evidently shown at $0.05 \%$ of Boron.

Then the curve decreases for almost the same previous value, about $160 \mathrm{~W} / \mathrm{m} \mathrm{C}$ in this time.

3.2. Microstructure Results. The morphology of the microstructure of all specimens is shown via an optical microscope (Hund 600) after surfaces preparation and etching them in the chemical solution $\left(1 \mathrm{~cm}^{3} \mathrm{HF}, 1.5 \mathrm{~cm}^{3} \mathrm{HCl}, 2.5 \mathrm{~cm}^{3} \mathrm{HNO} 3\right.$, and $95 \mathrm{~cm}^{3} \mathrm{H} 2 \mathrm{O}$ ).

The microstructure of the specimens without any addition is shown in Figure 6(a). We show in the same figure some microstructures with Titanium addition on the Aluminium 6063 (B with 0.3\% Ti and C with 1.5\% Ti) (Figure 6).

A kind of precipitation can be evidently shown in the microstructure in this metal with the Titanium addition. This precipitation is little with small Titanium percentage, and it grows in function to the increase of Titanium percentage. 


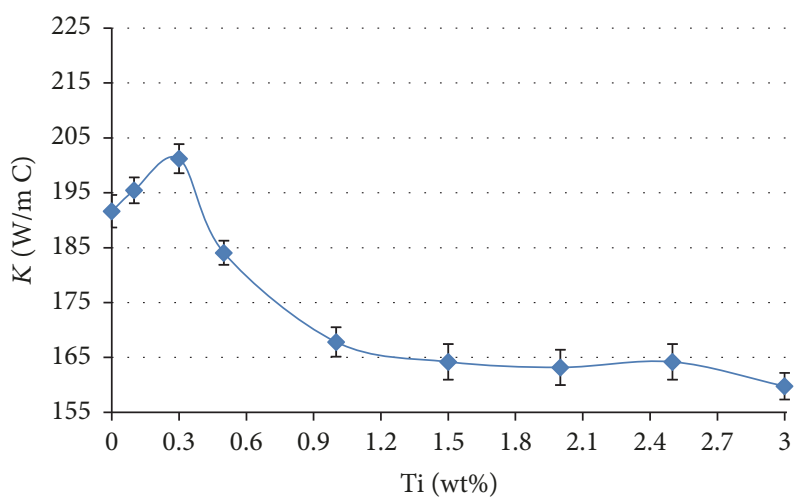

Figure 4: Mean of thermal conductivity ( \pm 3 standard deviation) versus addition percentage of Titanium. The measurements were done with mean temperatures of samples at $35^{\circ} \mathrm{C}$.

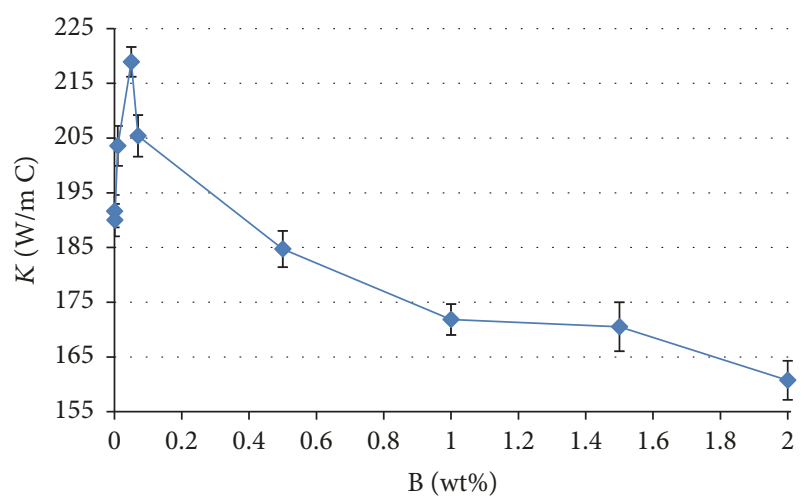

FIGURE 5: Mean of thermal conductivity ( \pm 3.5 standard deviation) versus addition percentage of Boron. The measurements were done with mean temperatures of samples at $35^{\circ} \mathrm{C}$.

The microstructure of specimens with Boron addition is presented in Figure 7: (a) without addition, (b) with $0.05 \%$ B, and (c) with $2 \% \mathrm{~B}$.

The addition of Boron accomplishes reduction in grains size and obtaining of new intermetallic phase with small size in these specimens.

3.3. Discussion. After casting and homogenization treatment of the Aluminium, we applied the solution treatment and the aging treatment to samples. The aging treatment is a very important process to stabilize the microstructure and proprieties of Aluminium. Our metal is designed for fabrication of heat sink elements for Central Processing Unit and submitted to an important change in the temperatures range.

Titanium has a positive influence on the improvement of thermal conductivity of Aluminium. Veijo also observed this result [7]. By adding a small amount of Titanium (until 0.3\% Ti), the thermal conductivity of Aluminium was improved until about 201 (W/m C).

In the microscope picture in Figure 6(b), we can see the precipitation of Al-Ti which started to form the specimen of $0.3 \% \mathrm{Ti}$, which appeared to be and remained small. The increase in thermal conductivity was due to the influence of Titanium on the Aluminium alloy and reducing its grains size per increasing the grains density; this effect was confirmed also by others $[7,20]$.

However, when the precipitation in the microstructure becomes significantly greater, an inconvenient evolution on thermal conductivity can be produced on the thermal conductivity curve, where the thermal conductivity reduced proportionally with the increasing of the percentage of Titanium in the Aluminium alloy as is shown in Figure 6(c). A value of $160 \mathrm{~W} / \mathrm{m} \mathrm{C}$ was obtained with important augmentation of Titanium percentage in the alloy, about 3\%. Rana et al. stated that the amount of Titanium must be limited to little percentage to save the characteristics of the Aluminium [14].

The influence of Boron on the thermal conductivity is more important than that of Titanium. There was a less percentage of element for the case of Boron addition. The curve showed an important augmentation directly at starting with a peak point at $0.05 \%$ of Boron, and then the tendency was decreasing with the increasing of the amount of Boron. The thermal conductivity arrived here at $219 \mathrm{~W} / \mathrm{m} \mathrm{C}$ for the peak, and then it decreased for last value of $160 \mathrm{~W} / \mathrm{m} \mathrm{C}$.

The Boron has also an influence of refining of grain size of the microstructure of Aluminium [18]. The images in Figure 7 showed that the grains size was smaller when we increased the Boron percentage in Aluminium alloy. The increasing of thermal conductivity is more important here with smaller ratio of Boron per rapport to the case of Titanium. That is due to the greater refining effect of grain size per rapport to the initial grain size. The influence of Boron on the refining of grain is more important per rapport to Titanium influence [7].

Methodically this effect must continue in its influence to increase the thermal conductivity by reducing grains size. However, this is not achieved because of the formation of intermetallic phase, AlB2 phase [18], in microstructure of the Aluminium, which has been revealed using X-Ray Diffraction (Philips PW 1830). In addition, it provides the reduction of the thermal conductivity of the metal.

We concluded that the influence of Titanium and Boron started from the casting step of the Aluminium. During the solidification stage, these additional elements increased the nucleus number density in the molten metal. This step is very important to build the grains structure of the metal. With this system of nucleation, we can have a limit in the growth step of the grains, and we obtained small grains size in the microstructure. This diminution of grain size improved the thermal conductivity coefficient of the Aluminium, but the improvement was still limited by small amount of addition elements, Titanium $(0.3 \%)$ and Boron $(0.05 \%)$. At these values, we noted the apparition of precipitation on the case of Titanium addition, but it was very small or negligible in the case of Boron addition. This explains how the improvement is more important with Boron addition.

If we continue adding these elements in the molten Aluminium, the grains size continues to be smaller, especially in the case of Boron addition, and the precipitations become more important in the case of Titanium addition. This explains also the smaller conductivity coefficient values in Titanium addition case after the peak compared to the case of Boron addition. The decreases of the thermal conductivity 


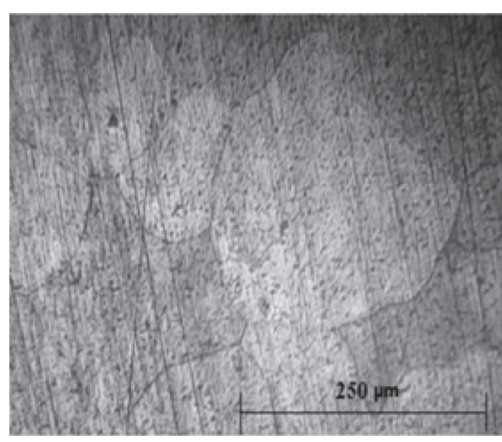

(a)

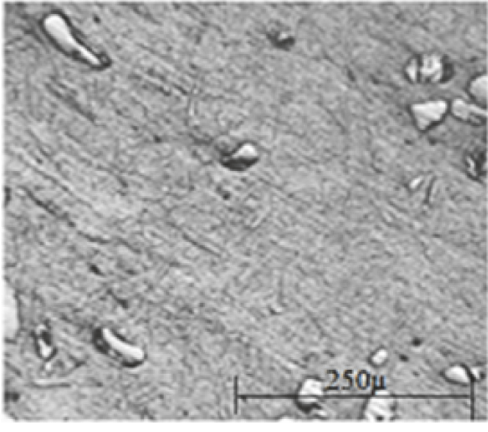

(b)

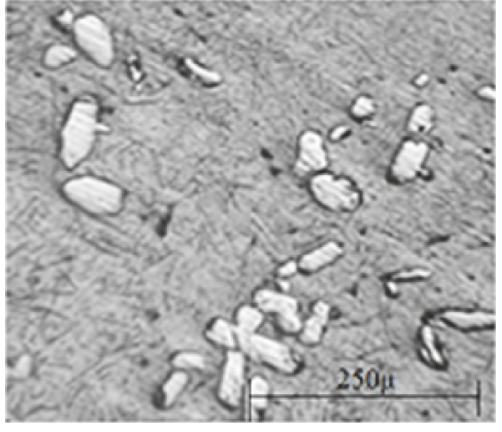

(c)

Figure 6: The morphologies of Aluminium 6063 without addition (a), with $0.3 \% \mathrm{Ti}$ (b), and with 1,5\% Ti (c).

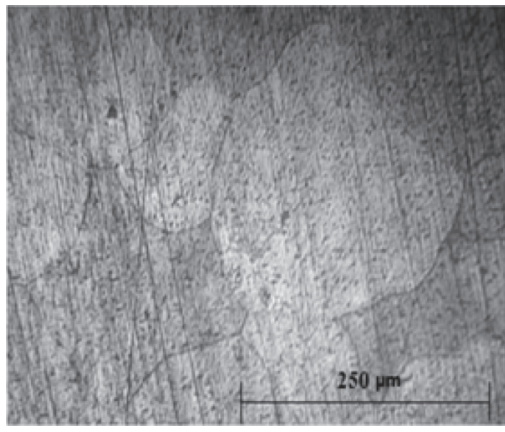

(a)

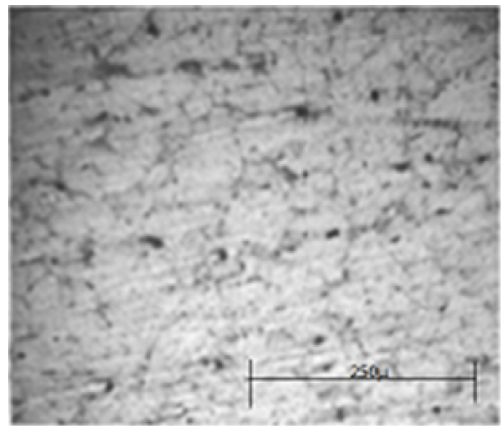

(b)

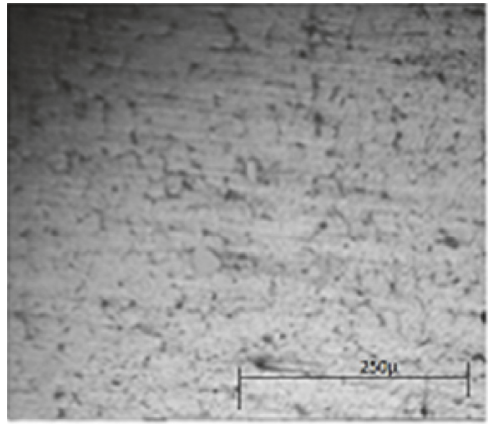

(c)

FIGURE 7: The morphologies of Aluminium 6063 without any addition (a), with $0.05 \%$ B (b), and with 2\% B (c).

coefficient in these two cases after the peaks can be explained by the effect of increasing of the heterogeneity in the basic metal.

The additional percentage of Boron increases the metal impurity. Additional augmentation of Titanium increases the density of precipitations and their volume. All those factors are considered as obstacles in front of heat dissipation and explain the decrease of final thermal conductivity coefficient.

\section{Conclusion}

Addition of some chemical elements can lead to increasing the thermal conductivity of the Aluminium 6063 for heat sinks applications used for electronic industries.

Titanium and Boron have a good effect in this way but only with small percentage.

More than $13 \%$ of improvement of the thermal conductivity was achieved with the addition of $0.05 \%$ of Boron and about $6 \%$ for $0.3 \%$ of Titanium addition.

Although these additions reduced the grains size, they attempted to form new intermetallic phases in the microstructures.

And these new phases lead to reducing the new thermal conductivity values already improved in the Aluminium 6063.

\section{Conflicts of Interest}

The authors declare that there are no conflicts of interest regarding this manuscript.

\section{References}

[1] I. Lavrov, "Temperature of the central processing unit," Undergraduate Journal of Mathematical Modeling: One + Two, vol. 7, no. 1, article 3, 2016.

[2] E. M. Sparrow, Y. I. Cho, J. P. Abraham, and J. M. Gorman, Advances in Heat Transfer, vol. 45, Academic Press Publications, Cambridge, Mass, USA, 2013.

[3] M. L. Minges, Electronic Materials Handbook Volume 1: Packaging, ASM International Handbook Committee, 1st edition, 1989.

[4] Q. A. Acton, Light Metals-Advances in Research and Application: ScholarlyBrief, ScholarlyEditions, Georgia, Ga, USA, 2013.

[5] N. Putra, Yanuar, and F. N. Iskandar, "Application of nanofluids to a heat pipe liquid-block and the thermoelectric cooling of electronic equipment," Experimental Thermal and Fluid Science, vol. 35, no. 7, pp. 1274-1281, 2011.

[6] D. D. L. Chung, "Materials for thermal conduction," Applied Thermal Engineering, vol. 21, no. 16, pp. 1593-1605, 2001.

[7] V. Rauta, On the effect of heat and metallurgical treatments on the thermal conductivity of cast-Aluminium alloys [Ph.D. thesis], Aalto University, School of Engineering, Department 
of Engineering Design and Production Materials Engineering, Aalto University Publication, Materials Engineering, Espoo, Finland, 2015.

[8] S. Mustafa and C. A. El Segundo, "Application Note AN-1057, 'Heat sink Characteristics"' in Proceedings of the International IOR Rectifier, Aavid Thermalloy Thermal Seminar, November 2002.

[9] K. C. Ng, C. R. Yap, and M. A. Chan, "A universal performance chart for CPU cooling devices," Heat Transfer Engineering, vol. 29, no. 7, pp. 651-656, 2008.

[10] V. K. Dwivedi, R. Gopal, and S. Ahmad, "Fabrication of very smooth walls and bottoms of silicon microchannels for heat dissipation of semiconductor devices," Microelectronics Journal, vol. 31, no. 6, pp. 405-410, 2000.

[11] S. Kang, D. Miller, and J. Cennamo, "Closed loop liquid cooling for high performance computer systems," in Proceedings of the IPACK2007, InterPACK Conference collocated with the ASME/JSME 2007 Thermal Engineering Heat Transfer Summer Conference, ASME 2007, vol. 2, pp. 509-515, Vancouver, British Columbia, Canada, July 2007.

[12] T. Lu and C. Chen, "Thermal transport and fire retardance properties of cellular aluminium alloys," Acta Materialia, vol. 47, no. 5, pp. 1469-1485, 1999.

[13] M. Shaira and M. Mounajeed, "Study and elaboration bi-metals (Aluminium-Copper) for improve the electrical conductivity," Journal of Al-Baath University, vol. 32, 2010.

[14] R. S. Rana, R. Purohit, and S. Das, "Reviews on the influences of alloying elements on the microstructure and mechanical properties of aluminum alloys and aluminum alloy composites," International Journal of Scientific and Research Publicationss, vol. 2, no. 6, 2012.

[15] G. K. Sigworth, "The grain refining of aluminum and phase relationships in the Al-Ti-B System," Metallurgical Transactions $A$, vol. 15, no. 2, pp. 277-282, 1984.

[16] J. Shin, S. Ko, and K. Kim, "Development of low-Si aluminum casting alloys with an improved thermal conductivity," Materiali in Tehnologije, vol. 48, no. 2, pp. 195-202, 2014.

[17] F. Stadler, H. Antrekowitsch, W. Fragner, H. Kaufmann, and J. Peter, "The effect of nickel on the thermal conductivity of AlSi cast alloys," in Proceedings of the ICAA13: 13th International Conference on Aluminum Alloys, (The Minerals, Metals \& Materials Society), 2012.

[18] K. Andreas, M. Rosefort, M. Christina, and K. Hubert, Improved Properties Of Aluminium Cast Alloys Due To A Boron Grain Refinement, Data sheet, TRIMET Aluminum G, Aluminiumallee 1, 45356 Essen, Germanyy.

[19] A. Tohru et al., ASM Handbook, Volume 4: Heat Treating, vol. 2, ASM, International, ASM Handbook Committee, 1991.

[20] I. Maxwell and A. Hellawell, "A simple model for grain refinement during solidification," Acta Metallurgica et Materialia, vol. 23, no. 2, pp. 229-237, 1975. 


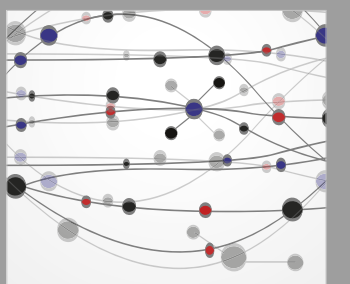

The Scientific World Journal
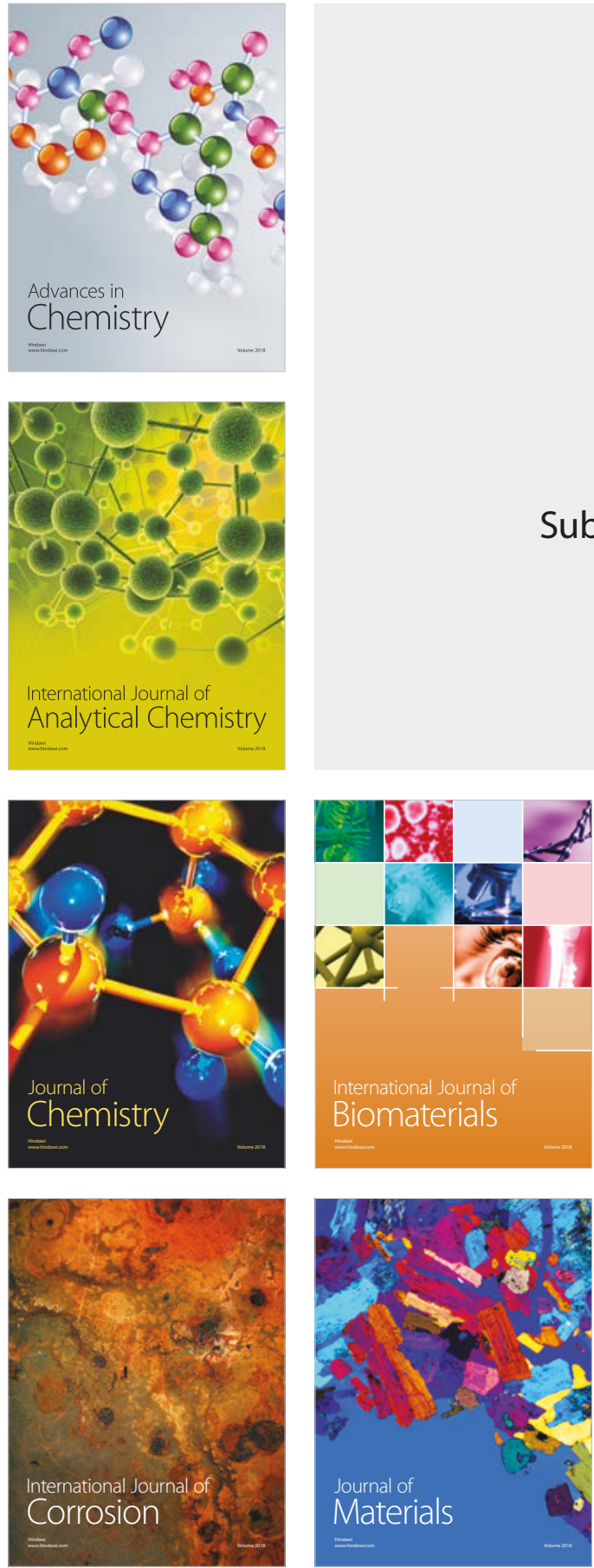

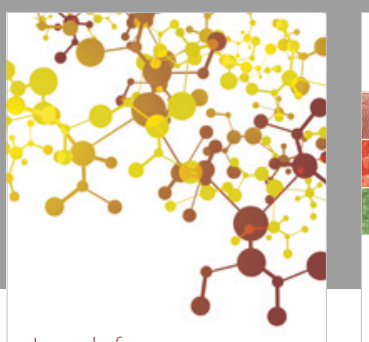

Journal of

Applied Chemistry
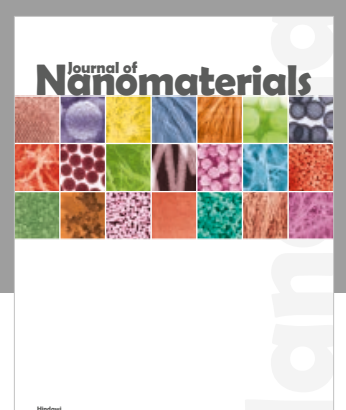

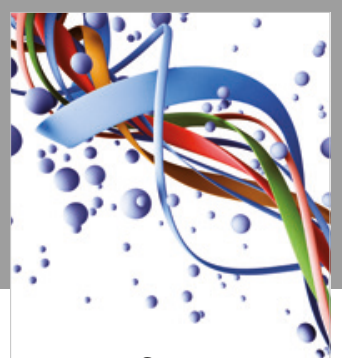

Scientifica

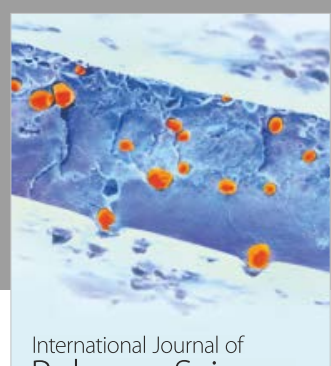

Polymer Science

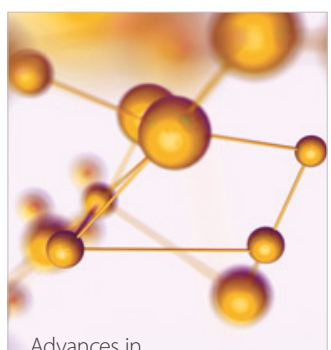

Physical Chemistry
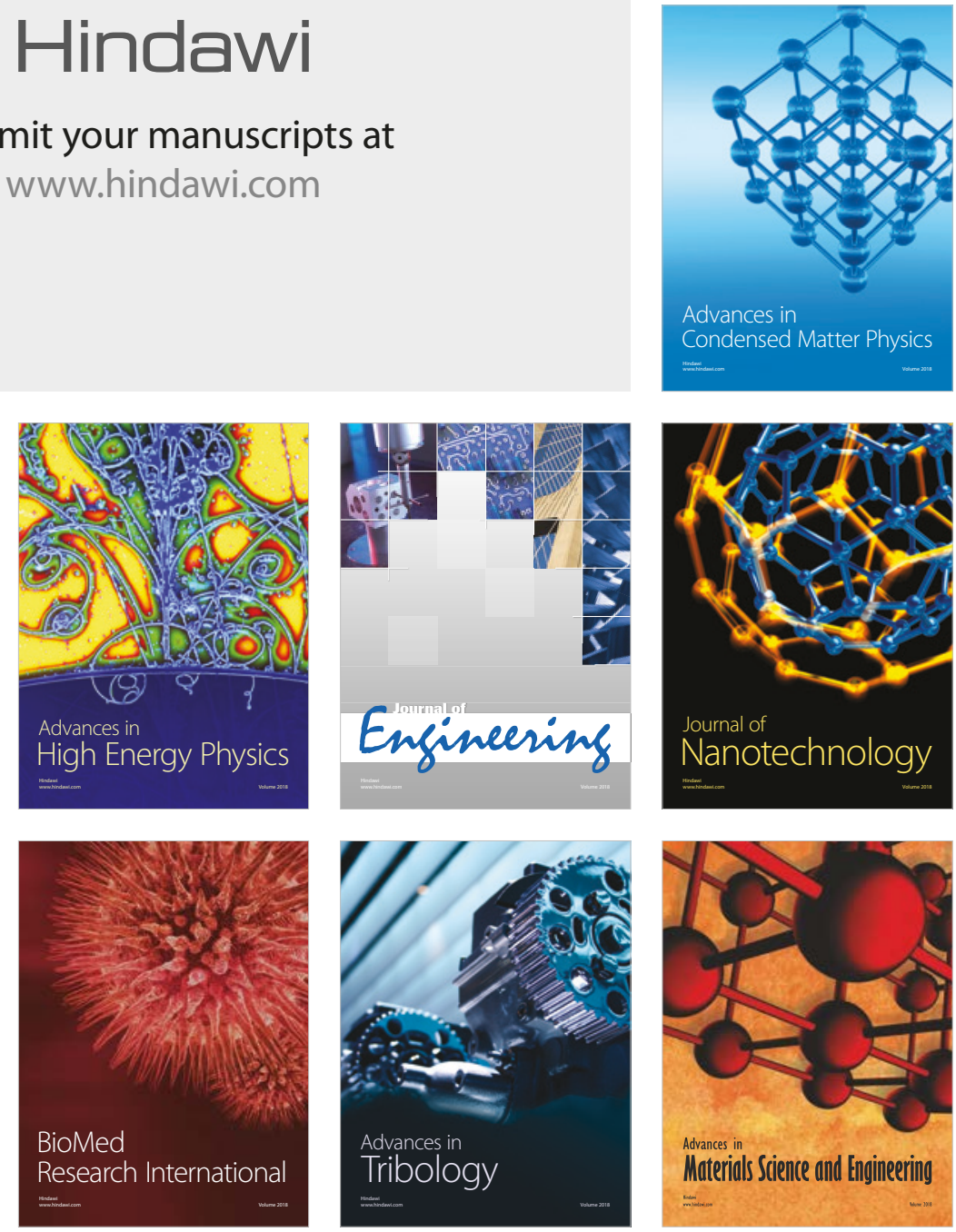